\title{
MICROLEAKAGE OF TEMPORARY CROWNS WITH DIFFERENT CEMENT GAP
}

\author{
Ahmed Yousef Elbieh**, Khaled Mohamed Haggag ** , Hesham Ibrahim Othman**
}

\begin{abstract}
Objective: To evaluate the effect of different cement gap on microleakage of PMMA crowns cemented with resin cement. Materials and Methods: Thirty natural human molar teeth were collected, the root of the teeth was sealed with a double layer of varnish for insulation to a level of $1 \mathrm{~mm}$ below the preparation margin, and mounted in an acrylic mold. Teeth were prepared through CNC, PMMA crowns fabricated by CAD/CAM. Samples were divided into 3 subgroups according to the cement gap

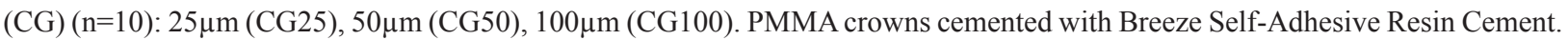
Samples were thermocycled for 5000 cycles between two water baths at $5{ }^{\circ} \mathrm{C}$ and $55^{\circ} \mathrm{C}$ with a dwell time of 20 seconds and 10 seconds of transfer time. Samples were immersed in methylene blue dye solution for 24 hours, then sectioned buccolingually. Dye penetration was assessed using a spectromicroscope, and then a score assessment was done for the microleakage. Results: The CG50 group scored the lowest median microleakage score, followed by CG100, and finally, CG25. The CG25 group; showed a statistically significantly higher median microleakage score than CG50 or CG100 groups. Conclusion: The cement gap has an effect on the microleakage of PMMA crowns cemented with self-adhesive resin cement.
\end{abstract}

KEYWORDS: Cement gap, Microleakage, PMMA, Resin cement

\section{INTRODUCTION}

The long-term success of restorations depends on cement properties such as cement type, physical and mechanical properties of the luting agent, placement techniques, seating force and environmental conditions $^{(1)}$.

Dental luting agents act as a link between the supported tooth prepared and the FDPs. Cements have developed steadily over the past decades. Resin cements have the property to adhere to both the internal surface of the restoration and the tooth structure. The adhesion mechanism of earlier resin cements was mostly micromechanical, but newer cements, especially those containing self-etch primers and acidic monomers, have been shown to bond chemically to the tooth structure and restoration as well ${ }^{(2)}$.

Because of their high bond strengths to the tooth structure, the resin cements provide more retention than conventional luting cements. However, they require multiple steps, are challenging to clean up, and are more technique sensitive than conventional cements $^{(2)}$.

Self-adhesive resin cements have been developed in an attempt to decrease bonding steps and improve ease of use. This approach combines the

* Doctorate candidate, Crown and Bridge Department, Faculty of Dental Medicine (Boys- Cairo) Al-Azhar University

** Professor, Crown and Bridge Department, Faculty of Dental Medicine (Boys- Cairo) Al-Azhar University

-Corresponding author: dr.elbieh@gmail.com 
adhesive and the cement in one step. Examples include Breeze self-adhesive resin cement. Clinicians may choose these cements because of their simplicity and, therefore, their reduced potential for application errors ${ }^{(3)}$.

Long-term temporization for more than six months made from semi-definite materials may be needed in some cases. As stated by the German Society of Dental, Oral and Craniomandibular Sciences (DGZMK) $)^{(4)}$, such long-term temporaries are indicated for treatment including changes of vertical dimension, aesthetics or phonetics, for palliative prosthodontic treatment in cancer patients and for bridging the time of healing or exploring potential abutment teeth with unclear prognosis for definitive restorative treatment later in time. All these objectives may need temporaries for about one year and or even longer time.

Microleakage, which enables the infiltration of micro-organisms, liquid, and chemical substances from the oral environment along with the tooth/ restoration interface, is one of the most critical issues to test the luting cement. This can lead to the accumulation of bacteria, causing postoperative pain, recurrent caries, or pulp damage, which are the most common reasons for failure to recover ${ }^{(5,6)}$.

Cement gap, also known as die spacer, is an essential factor in microleakage prevention, it helps to reduce the resistance to flow of cementing material, enabling full restore seating and providing an excellent marginal seal. The flow resistance of cementing materials may result in the crown's incomplete seat that may generate marginal inconsistencies and subsequent microleakage ${ }^{(7)}$.

An essential cause of a microleakage is the thermal fluctuation occurring in the oral cavity. The hot and cold temperatures are stressed cyclically by changes in the thermal expansion factor of the tooth and the combing cement at the tooth cement interface. These stress-induced were resisted only from binding strength and could lead to a micro gap with a low bond strength on the tooth cement interface $^{(8)}$.

Although the importance of clinical studies and their realistic results may be retained and scaled by in vitro evaluation, the bioactive combinable cement may be considered sensitively. Aim of this study was to evaluate the effect of different cement gap on microleakage of PMMA crowns cemented with resin cement. Hypothesis was the smallest cement gap will perform better against microleakage.

\section{MATERIALS AND METHODS}

Thirty natural human molar teeth were freshly extracted due to periodontal problems, examined under the magnifying lens to be clear of any defects, caries, or cracks, then washed, preserved for two weeks in $0.1 \%$ chloramine solution and then at room temperature in distilled water.

The root surfaces of the teeth were sealed with a double layer of varnish for insulation to a level of $1 \mathrm{~mm}$ below the preparation margin. Polyvinyl chloride (PVC) cylinder of $2.5 \mathrm{~cm}$ diameter was cut into an equal length of $2 \mathrm{~cm}$ to be used as a mold. A centralizing device was used to standardize the mounting of each tooth in a vertical direction within the mold to allow accurate centralization of the teeth within the acrylic mold.

A computer numerical control (CNC) (CNC Premium 4820-i-mes, Germany) unit was used to standardize teeth preparation to receive a full-coverage crown $^{(9)}$.The Preparation design was round shoulder finish line with thickness $1 \mathrm{~mm}$, flat occlusal surface, $20^{\circ}$ total convergence, and $4 \mathrm{~mm}$ high.

Temporary crowns were fabricated from Polymethyl methacrylate (PMMA) (Yamahachi PMMA Disk; Yamahachi Dental Mfg Co, Gamagori, Japan), using CAD/CAM, (Roland dwx 52D, Roland, Hamamatsu, Japan).

Samples were divided randomly into three subgroups according to the cement gap setting of the CAD/CAM $(\mathrm{n}=10)$ 
a. Cement gap $25 \mu \mathrm{m}$ (CG25)

b. Cement gap $50 \mu \mathrm{m}$ (CG50)

c. Cement gap $100 \mu \mathrm{m}$ (CG100)

PMMA crowns were cemented on prepared teeth using Breeze Self-Adhesive Resin Cement (Pentron Clinical Technologies, Wallingford, Ct, USA), which is an automix dual-cure self-adhesive resin cement.

Adhesive cement was used according to manufacturer's instruction, and a static load of 50 $\mathrm{N}$ placed over the samples for 5 minutes using a specially designed loading device ${ }^{(10)}$, excess cement was removed after initial setting by using explorer. After complete setting and polymerization of the luting cements, samples were placed in distilled water for 24 hours to allow the relief of internal stresses of the cement.

All samples underwent thermocycling for 5000 cycles which simulated 6 month of service in the oral cavity ${ }^{(11)}$ between two water baths at $5^{\circ} \mathrm{C}$ and $55^{\circ} \mathrm{C}$ with a dwell time of 20 seconds in each bath and 10 seconds of transfer time between the two baths.

Samples were immersed in methylene blue dye solution (Loba Chemie, Mumbai, India) for 24 hours in an incubator at $37^{\circ} \mathrm{C}^{(12)}$, then washed out with running tap water to remove the residual dye. Samples were sectioned buccolingual using a diamond wheel (Isomet 5000, Buehler, USA).

Dye penetration was assessed using a spectromicroscope (Nikon MA 100, Japan) with $50 \mathrm{X}$ magnification. Image analysis was performed using computer software Omnimet (Buehler, USA) and recorded in micrometer $(\mu \mathrm{m})$.

A score assessment was recorded, according to Tjan et al. ${ }^{(13)}$ where : $0=$ absence of dye penetration; $1=$ microleakage to one-third of the axial wall; $2=$ microleakage to two-thirds of the axial wall; $3=$ microleakage along the full length of the axial wall; 4=microleakage over the occlusal surface.
Collected data was tabulated, and statistical analysis was performed with IBM SPSS Statistics for Windows, Version 23.0 (Armonk, NY: IBM Corp.).

\section{RESULTS}

Ordinal data were represented by mean and standard deviation (SD) values, and they were analyzed using the Kruskal Wallis test followed by multiple pairwise comparisons utilizing Dunn's post hoc test. The significance level was set at $\mathrm{p} \leq 0.05$.

There was a significant difference between the microleakage scores in samples with different gap distances $(p<0.001)$. The highest microleakage scores were found CG25 (2.36 \pm 0.21$)$ followed by CG100 (1.75 \pm 0.14$)$ while the lowest scores with found in samples with CG50 (1.66 \pm 0.20$)$.

Pairwise comparisons showed CG 25 to have a significantly higher microleakage score than samples with other gap distances $(\mathrm{p}<0.001)$.

TABLE (1) Mean \pm standard deviation (SD) of microleakage scores for different cement gap.

\begin{tabular}{|c|c|c|c|c|}
\hline \multirow{2}{*}{$\begin{array}{c}\text { Cement } \\
\text { type }\end{array}$} & \multicolumn{3}{|c|}{ Cement gap (mean \pm SD) } & \multirow{2}{*}{ p-value } \\
\cline { 2 - 4 } & CG25 & CG50 & CG100 & \\
\hline Resin (PRC) & $2.36 \pm 0.21^{\mathrm{A}}$ & $1.66 \pm 0.20^{\mathrm{B}}$ & $1.75 \pm 0.14^{\mathrm{B}}$ & $<0.001^{*}$ \\
\hline
\end{tabular}

Different superscript letters indicate a statistically significant difference within the same horizontal row*; significant $(p \leq 0.05)$ ns; non-significant ( $p>0.05)$

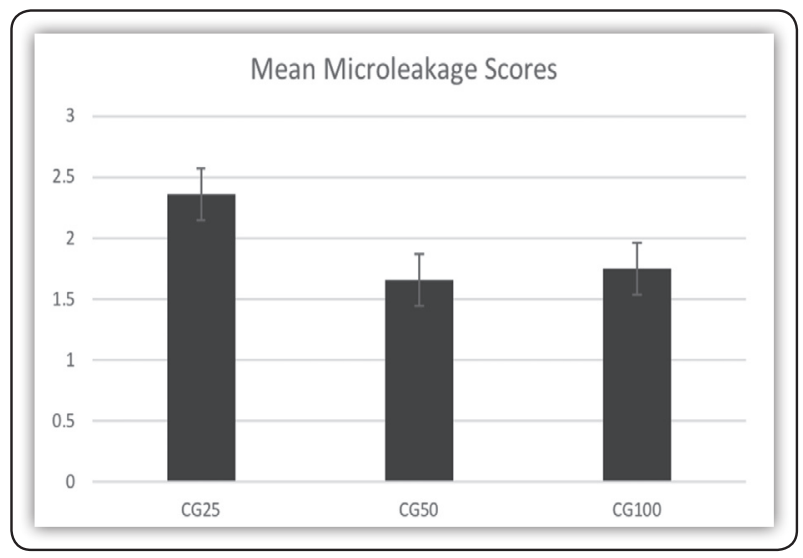

FIG (1) Bar chart showing mean microleakage sores for different cement gaps. $\mathrm{CG}=\mathrm{Cement}$ Gap 


\section{DISCUSSION}

Dental luting cements play a vital role in the success of indirect restorations. The primary function of the luting cement is to fill the gap between the prepared tooth and indirect restoration, in addition to mechanically or chemically bonding the restoration to the preparation to prevent dislodgement during the function. A final property is to enhance the color of the esthetic all-ceramic restoration ${ }^{(14-16)}$.

Resin cements have gained popularity in the dental market during recent years due to high compressive and tensile strengths, low solubility, and favorable esthetic qualities. In addition, in vitro, and in vivo studies suggest that resin bonding helps diffuse stress and limit crack propagation on the internal aspect of porcelain restorations ${ }^{(17)}$. However, they are expensive and have the disadvantages of being technique sensitive, easily contaminated during multiple-step application procedures, and difficult and time-consuming during clean-up ${ }^{(18)}$.

Microleakage test using dye was also performed to assess the effectiveness of the sealing ability of bioactive cement to prevent or decrease the microleakage underneath the prosthesis.

Numerous methods and techniques have been utilized to investigate microleakage, cross-sectional view, direct view, air pressure, fluid filtration, electrochemical, and radioisotope methods, with the dye penetration technique being the most popular $\operatorname{method}^{(19)}$. This method gained its popularity because of its feasibility and simplicity and was used in the current study.

Various tracers have been used (such as basic fuchsin, eosin, methylene blue, and silver nitrate). One study reported that basic fuchsin was used most often in previous studies (40.7\%) followed by methylene blue (22\%) and silver nitrate $(17 \%)^{(20)}$. In this study, the teeth were immersed in $2 \%$ methylene blue dye solution for $24 \mathrm{~h}$.
The sealing ability of any cement is affected by mechanical, physical, and chemical properties of that cement, which depend mainly on its chemical composition. In general, cements with desirable mechanical properties, dimensional stability, excellent adhesion to the tooth structure, low film thickness, low solubility in oral fluids, and a similar coefficient of thermal expansion to the coronal tooth structure typically possess excellent sealing abilities ${ }^{(21)}$.

The CG50 group scored the lowest median microleakage score, followed by CG100, and finally CG25, (1.66 \pm 0.20$),(1.75 \pm 0.14)$, and (2.36 \pm 0.2$)$.

The results revealed that either CG50 or CG100 groups, there was no statistically significant difference between the median microleakage scores. However, the CG25 group; showed a statistically significantly higher median microleakage score than CG50 or CG100 groups.

The CG25 group scored the highest microleakage score, and this may be attributed to incomplete seating of the crown or due to increased cement film thickness.

On the opposite side, CG50 scored the lowest microleakage score, which may be caused by a better seating of the crown and better margin seal which decrease microleakage, as Kale et al. found that increasing cement space decreased the marginal discrepancy ${ }^{(22)}$.

The high number of thermocycling (5000 cycles), which simulate six months of service in the oral cavity ${ }^{(11)}$, may have caused some dimensional changes in the PMMA. Moreover, this may have affected the bond between the cement and the PMMA surface. Moreover, the adhesion of both cement with the Pmma is not known

\section{CONCLUSION}

Within the limitation of this study, it was concluded that cement space affects the microleakage of PMMA crowns cemented with self-adhesive resin cement. 


\section{REFERENCES}

1. Haselton DR. Contemporary Fixed Prosthodontics. J Prosthodont. 2004 Aug 9;11(3):227-8.

2. Sunico-Segarra M, Segarra A. A Practical Clinical Guide to Resin Cements. 1st ed. A Practical Clinical Guide to Resin Cements. Berlin, Heidelberg: Springer Berlin Heidelberg; 2015. 4 p.

3. Vargas MA, Bergeron C, Diaz-Arnold A. Cementing all-ceramic restorations. J Am Dent Assoc. 2011 Apr;142:20S-24S.

4. Handel G. Wissenschaftliche Stellungnahme der DGZMK: Langzeitprovisorien. Dtsch Zahnärztl. 2002;57:450.

5. Al-Saleh M, El-Mowafy O, Tam L, Fenton A. Microleakage of Posterior Composite Restorations Lined with Self-adhesive Resin Cements. Oper Dent. 2010 Sep;35(5):556-63.

6. Trajtenberg CP, Caram SJ, Kiat-amnuay S. Microleakage of All-ceramic Crowns Using Self-etching Resin Luting Agents. Oper Dent. 2008 Jul;33(4):392-9.

7. Pilo R, Cardash HS, Baharav H, Helft M. Incomplete seating of cemented crowns: A literature review. J Prosthet Dent. 1988 Apr;59(4):429-33.

8. Schmid-Schwap M, Graf A, Preinerstorfer A, Watts DC, Piehslinger E, Schedle A. Microleakage after thermocycling of cemented crowns-A meta-analysis. Dent Mater. 2011 Sep;27(9):855-69.

9. Sha'aban AM, El Naggar GA, Nabil R, Rashad MA, Attia YS. Wear assessment of current aesthetic crowns compared with human enamel after two finishing procedures: In vitro study. F1000Research. 2019 Jul 17;8:1115.

10. Yim NH, Rueggeberg FA, Caughman WF, Gardner FM, Pashley DH. Effect of dentin desensitizers and cementing agents on retention of full crowns using standardized crown preparations. J Prosthet Dent. 2000 Apr;83(4):459-65.

11. Gale M., Darvell B. Thermal cycling procedures for laboratory testing of dental restorations. J Dent. 1999 Feb;27(2):89-99.
12. Pittayachawan P, Lerdrit W, Owittayakul D. Microleakage of zirconia frameworks cemented with two types of phosphate monomer-based resin cements. Eur J Gen Dent. 2015;4(2):92.

13. Tjan AHL, Dunn JR, Grant BE. Marginal leakage of cast gold crowns luted with an adhesive resin cement. J Prosthet Dent. 1992 Jan;67(1):11-5.

14. Edelhoff D, Ozcan M. To what extent does the longevity of fixed dental prostheses depend on the function of the cement? Working Group 4 materials: cementation. Clin Oral Implants Res. 2007 Jun;18 Suppl 3:193-204.

15. Rosenstiel SF, Land MF, Crispin BJ. Dental luting agents: A review of the current literature. J Prosthet Dent. 1998 Sep;80(3):280-301.

16. Krämer N, Lohbauer U, Frankenberger R. Adhesive luting of indirect restorations. Am J Dent. 2000 Nov; 13(Spec No):60D-76D.

17. Burke FJT, Fleming GJP, Nathanson D, Marquis PM. Are adhesive technologies needed to support ceramics? An assessment of the current evidence. J Adhes Dent. 2002;4(1):7-22.

18. Pace LL, Hummel SK, Marker VA, Bolouri A. Comparison of the Flexural Strength of Five Adhesive Resin Cements. J Prosthodont. 2007 Jan;16(1):18-24.

19. Nguyen C. A new in vitro method for the study of microleakage of dental restorative materials. PhD diss., 2007.

20. Raskin A, D’Hoore W, Gonthier S, Degrange M, Déjou J. Reliability of in vitro microleakage tests: a literature review. J Adhes Dent. 2001;3(4):295-308.

21. Farah, RI. Elzeky M. An in vitro comparison of marginal microleakage of four groups of temporary cements in provisional crowns. Int J Adv Res. 2015;3(3):778-87.

22. Kale E, Seker E, Yilmaz B, Özcelik TB. Effect of cement space on the marginal fit of CAD-CAM-fabricated monolithic zirconia crowns. J Prosthet Dent. 2016 Dec;116(6):890-5. 